\title{
Is Obesity Significantly Related to Early Onset and Progression of Knee Osteoarthritis?
}

\author{
Karan Jindal ${ }^{1}$, Sarvdeep S Dhatt ${ }^{2}$, Mandeep S Dhillon ${ }^{3}$
}

\begin{abstract}
Obesity is a modifiable risk factor that is associated with osteoarthritis (OA). The pathogenesis is multifactorial which includes mechanical, humoral, and genetic factors. We discuss the role of obesity in this article in the early onset and progression of knee OA and whether there is a correlation with arthroplasty and the prevention of obesity with OA in the obese population.

Keywords: Obesity, Osteoarthritis, Progression.

Journal of Postgraduate Medicine, Education and Research (2021): 10.5005/jp-journals-10028-1428
\end{abstract}

Knee osteoarthritis (OA) is classified as a degenerative disease of the joint with localized loss of cartilage and associated inflammation. ${ }^{1}$ Clinically, it presents as pain, stiffness, limitation in movement, and joint deformities. It is one of the leading causes of disability in the elderly population and substantially impacts the quality of life. ${ }^{2}$

One of the important risk factors associated with OA is obesity. This article assesses the impact of obesity on the onset and progression of knee OA.

\section{Pathogenesis}

The association of obesity causing overloading of the weightbearing joint and resultant wear and tear of the cartilage is obvious. ${ }^{3}$ However, this association with obesity is not as direct and several factors including mechanical, humoral, and genetic factors contribute to the pathogenesis of knee OA.

Mechanical factors cause OA due to the increased axial pressure on the joint. Moyer et al. $^{3}$ showed this relationship showing an association between body mass and dynamic knee loading. These abnormal loads alter the composition and mechanical properties of hyaline cartilage ultimately leading to erosion of the cartilage. Messier et al. ${ }^{4}$ in their study of gait analysis of 142 overweight individuals with knee OA observed that each pound of weight loss resulted in a four-fold reduction of load exerted on the knee joint.

Even in other joints, an association of OA with obesity has been documented. Studies have shown an increased risk of hand OA by 2-4 times in obese people as compared to normal-weight people. ${ }^{5}$ Osteoarthritis develops when a breakdown of cartilage is faster than it is produced. Obesity has been seen to be associated with higher levels of insulin-like growth factor-1 (IGF-1) levels and proinflammatory cytokines due to the compression of the mechanoreceptors at the surface of chondrocytes. ${ }^{6}$ These are understood to cause additive oxidative stress, inflammation, and tissue breakdown at the knee joint. Additionally, adipose tissue found in abundance in obese patients secretes leptin, resistin, and adiponectin which may influence cartilage homeostasis and have a role between obesity and OA of the knee.

There is also a growing understanding of the genetic basis of $\mathrm{OA}$; however, there are conflicting views regarding its association with obesity. Spector et al. ${ }^{7}$ found a correlation in twins while Manek et al. ${ }^{8}$ concluded that the association was unlikely to be mediated by shared genetic factors.
${ }^{1-3}$ Department of Orthopaedics, Postgraduate Institute of Medical Education and Research, Chandigarh, India

Corresponding Author: Karan Jindal, Department of Orthopaedics, Postgraduate Institute of Medical Education and Research, Chandigarh, India, Phone: +91 9779925000, e-mail: karan.121@hotmail.com

How to cite this article: Jindal K, Dhatt SS, Dhillon MS. Is Obesity Significantly Related to Early Onset and Progression of Knee Osteoarthritis? J Postgrad Med Edu Res 2021;55(1):36-38.

Source of support: Nil

Conflict of interest: None

\section{Early Obesity and Osteoarthritis Development}

It is a known fact that childhood obesity predicts adult obesity. Whitaker et al. ${ }^{9}$ showed that adolescents who are overweight are 18 times more likely to become obese in their early adulthood as compared to normal-weight people. Several studies have identified that the ideal window of opportunity to prevent obesity is during adolescence and young adult life. ${ }^{10}$ Wills et al. ${ }^{11}$ suggested that obesity from childhood had an accumulative effect on knee OA development. The body mass index (BMI) in young people (as early as 15 years) was associated with an increased risk of OA at 53 years. They concluded that prolonged exposure to high BMI throughout adulthood carried the highest risk of knee OA. However, a study by Manninen et al. ${ }^{12}$ observed that the pattern of weight gain is important, with a higher risk of knee OA requiring arthroplasty seen in patients with a shift from normal to overweight in adult life when compared with being constantly overweight.

\section{Correlation of Obesity with OSTEOARTHRITIS}

Blagojevic et al. ${ }^{13}$ conducted a systematic review and observed that all studies showed obesity as a risk factor for knee OA. They demonstrated that the risk of developing $O A$ increased in proportion with an increase in weight. A study by Gelber et al. ${ }^{14}$ observed that there was a three-fold increase in the risk of OA for the patients in the obese group when compared with the normal-weight group in the younger population. The Framingham Osteoarthritis study

(c) The Author(s). 2021 Open Access This article is distributed under the terms of the Creative Commons Attribution 4.0 International License (https:// creativecommons.org/licenses/by-nc/4.0/), which permits unrestricted use, distribution, and non-commercial reproduction in any medium, provided you give appropriate credit to the original author(s) and the source, provide a link to the Creative Commons license, and indicate if changes were made. The Creative Commons Public Domain Dedication waiver (http://creativecommons.org/publicdomain/zero/1.0/) applies to the data made available in this article, unless otherwise stated. 
(mean age 37 years) showed that patients in the heaviest weight quintile had a $50 \%$ increase in the risk of radiographic knee OA at 36 years of follow-up. ${ }^{15}$ Hart et al. ${ }^{16}$ assessed BMI at 54 years and observed that BMI was predictive of incident osteophytes but not joint space narrowing. These results suggest that bodyweight in the early years may be a more important risk factor than weight in later years of life.

Varus malalignment is an important risk factor for the progression of knee OA. ${ }^{10}$ Sharma et al. ${ }^{17}$ observed that the severity of OA correlated with higher BMI in patients with varus knees but not in those with valgus knees.

Obesity has seen to be associated with an increase in the symptoms of knee pain which may or may not correlate radiologically. Webb et al. ${ }^{18}$ in a community-based study observed a three- to four-fold increase in knee pain with a rise in the BMI. Somers et al. ${ }^{19}$ observed that patients with higher BMI (borderline and morbidly obese) had significantly higher levels of pain when compared with a group of overweight patients.

Sahyoun et al. ${ }^{20}$ in their study showed that each unit in ageadjusted BMI was associated with a $4 \%$ increase in the incidence of OA. They also observed that the risk of OA was higher in those obese individuals who gained weight than those who were able to maintain their weight. Also, a loss of $10 \%$ of the body weight in the obese group reduced the risk to that of the non-obese population.

Coggon et al. ${ }^{21}$ conducted a population-based case-control study and observed that the odds ratio for developing OA with BMI $<20$ was 0.1 (95\% Cl 0.0-0.5) when compared with the odds ratio of 13.6 (95\% Cl 5.1-36.2\%) with BMI >35. They also said that the odds ratio increased to 78 with risk factors, such as, previous knee injury, previous meniscectomy, or the presence of Heberden nodes. They also observed that the risks associated with obesity tended to be higher in women when compared with men.

A case-control study by Holliday et al. ${ }^{22}$ recruited 1,042 knee OA patients and 1,121 controls and reported that patients with $\mathrm{BMI}>30$ had an adjusted odds ratio of 7.48 for knee OA $(95 \% \mathrm{Cl}$ $5.45-10.27)$ when compared with $\mathrm{BMI}<25$. Also, they observed that a greater duration of being overweight was associated with a higher risk of OA. Consequently, it appears that the severity of $O A$ and its incidence rises linearly with increasing BMI.

\section{Correlation with Arthroplasty}

The need for arthroplasty has been used as a marker of the severity of OA in obese patients by some studies. Lohmander et al. ${ }^{23}$ in their cohort of $>25,000$ patients between 45 years and 73 years of age found a significant relationship between BMl of $>30 \mathrm{~kg} / \mathrm{m}^{2}$ and need for hip or knee arthroplasty.

Several studies have found BMI to independently predict the need for arthroplasty at an earlier age group. Gandhi et al. ${ }^{24}$ in their study using univariate analysis observed that patients with BMI $>35 \mathrm{~kg} / \mathrm{m}^{2}$ had an arthroplasty 7-8 years earlier than those with normal weight. Changulani et al. ${ }^{25}$ observed that arthroplasty was undertaken at a younger age with an increase in BMl; however, statistical significance was seen with $\mathrm{BMI}>35 \mathrm{~kg} / \mathrm{m} .{ }^{2}$ Bourne et al. ${ }^{26}$ observed that a change from an individual's baseline BMI confers a greater risk, with an increase of $1 \mathrm{~kg} / \mathrm{m}^{2}$ of BMI resulting in a $10.5 \%$ risk of arthroplasty and a $5 \mathrm{~kg} / \mathrm{m}^{2}$ of BMI resulting in almost doubling the risk. Leyland et al. ${ }^{27}$ demonstrated that the index BMI was predictive of arthroplasty, with a $40 \%$ increase in risk in overweight patients and a 2.7 times higher risk in patients with $\mathrm{BMI}>40 \mathrm{~kg} / \mathrm{m}$.
The major issue with doing arthroplasty at an earlier age is that these patients may require revision surgery. These patients are also at a higher risk of perioperative complications which further increase the risk of reoperation. Nevertheless, there is also published data ${ }^{28}$ that suggest higher BMI does not predict earlier failure of arthroplasty.

\section{Obesity Reduction and Its Effect on Osteoarthritis}

Weight reduction is considered as a functional treatment for knee $\mathrm{OA}$ and is especially important in obese patients as it will lead to a reduction in the joint load and inflammation. However, there is little prospective data to confirm this assumption.

Christensen et al. ${ }^{29}$ in their review observed that a loss of $5 \%$ of the body weight over 20 weeks resulted in symptomatic relief. The Framingham Knee Osteoarthritis Study ${ }^{15}$ found that a reduction in BMI of approximately $5.1 \mathrm{~kg}$ over 10 years reduced the risk of developing OA by over $50 \%$. However, they did not address the effect of weight loss after the onset of symptoms.

Messier et al. ${ }^{4}$ in their series of 252 patients with a BMI $\geq 28$ reported that patients underwent dietary weight loss and physical therapy regime and a 5\% loss in weight over 18 months resulted in an $18 \%$ improvement in function. However, there were no radiological changes observed.

Another aspect is the surgical treatment of obesity. Bariatric surgery has been shown to improve the health-related quality of life and improvement in cardiovascular parameters. Abu-Abeid et al. $^{30}$ in their prospective study concluded that surgery is an effective and rapid mean of reversing the radiological sign of early changes associated with OA. Most studies report symptomatic and structural improvement with significant weight loss; however, a smaller degree of weight loss also benefits people and modifies the trajectory toward progression to clinically significant OA. ${ }^{31}$

\section{Conclusion}

Obesity is a modifiable risk factor that correlates with the early onset and progression of knee OA due to associated mechanical and humoral factors. Prevention and management of obesity is the primary intervention required and knee arthroplasty remains a viable option even in morbidly obese as it improves the functional outcome and quality of life.

\section{References}

1. National Institute for Health and Care Excellence. Osteoarthritis: care and management in adults. London, UK: National Institute for Clinical Excellence. 2014 Feb 24.

2. Cross M, Smith E, Hoy D, et al. The global burden of hip and knee osteoarthritis: estimates from the global burden of disease 2010 study. Ann Rheum Dis 2014;73(7):1323-1330. DOI: 10.1136/ annrheumdis-2013-204763.

3. Moyer RF, Birmingham TB, Chesworth BM, et al. Alignment, body mass and their interaction on dynamic knee joint load in patients with knee osteoarthritis. Osteoarthritis Cartilage 2010;18(7):888-893. DOI: 10.1016/j.joca.2010.03.017.

4. Messier SP, Gutekunst DJ, Davis C, et al. Weight loss reduces knee-joint loads in overweight and obese older adults with knee osteoarthritis. Arthritis Rheum 2005;52(7):2026-2032. DOI: 10.1002/art.21139.

5. YusufE, Nelissen RG, loan-Facsinay A, et al. Association between weight or body mass index and hand osteoarthritis: a systematic review. Ann Rheum Dis 2010;69(4):761-765. DOI: 10.1136/ard.2008.106930. 
6. Lloyd ME, Hart DJ, Nandra D, et al. Relation between insulin-like growth factor-I concentrations, osteoarthritis, bone density, and fractures in the general population: the Chingford study. Ann Rheum Dis 1996;55(12):870-874. DOI: 10.1136/ard.55.12.870.

7. Spector TD, Cicuttini F, Baker J, et al. Genetic influences on osteoarthritis in women: a twin study. BMJ 1996;312(7036):940-943. DOI: $10.1136 / \mathrm{bmj} .312 .7036 .940$.

8. Manek NJ, Hart D, Spector TD, et al. The association of body mass index and osteoarthritis of the knee joint: an examination of genetic and environmental influences. Arthritis Rheum 2003;48(4):1024-1029. DOI: 10.1002/art.10884.

9. Whitaker RC, Wright JA, Pepe MS, et al. Predicting obesity in young adulthood from childhood and parental obesity. N Eng J Med 1997;337(13):869-873. DOI: 10.1056/NEJM199709253371301.

10. Felson DT, Zhang Y. An update on the epidemiology of knee and hip osteoarthritis with a view to prevention. Arthritis Rheum 1998;41(8):1343-1355.DOI: 10.1002/1529-0131(199808)41:8<1343::AIDART3>3.0.CO;2-9.

11. Wills AK, Black $S$, Cooper R, et al. Life course body mass index and risk of knee osteoarthritis at the age of 53 years: evidence from the 1946 British birth cohort study. Ann Rheum Dis 2012;71(5):655-660. DOI: 10.1136/ard.2011.154021.

12. Manninen P, Riihimaki $H$, Heliövaara $M$, et al. Weight changes and the risk of knee osteoarthritis requiring arthroplasty. Ann Rheum Dis 2004;63(11):1434-1437. DOI: 10.1136/ard.2003.011833.

13. Blagojevic $M$, Jinks $C$, Jeffery $A$, et al. Risk factors for onset of osteoarthritis of the knee in older adults: a systematic review and meta-analysis. Osteoarthritis Cartilage 2010;18(1):24-33. DOI: 10.1016/j.joca.2009.08.010

14. Gelber AC, Hochberg MC, Mead LA, et al. Body mass index in young men and the risk of subsequent knee and hip osteoarthritis. Am J Med 1999;107(6):542-548. DOI: 10.1016/S0002-9343(99)00292-2.

15. Felson DT, Naimark A, Anderson J, et al. The prevalence of knee osteoarthritis in the elderly. The Framingham osteoarthritis study. Arthritis Rheum 1987;30(8):914-918. DOI: 10.1002/art.1780300811.

16. Hart DJ, Doyle DV, Spector TD. Association between metabolic factors and knee osteoarthritis in women: the Chingford study. J Rheumatol 1995;22(6):1118-1123.

17. Sharma L, Lou C, Cahue S, et al. The mechanism of the effect of obesity in knee osteoarthritis: the mediating role of malalignment. Arthritis Rheum 2000;43(3):568-575. DOI: 10.1002/ 1529-0131(200003)43:3<568::AID-ANR13>3.0.CO;2-E.

18. Webb R, Brammah T, Lunt $M$, et al. Opportunities for prevention of 'clinically significant'knee pain: results from a population-based cross sectional survey. J Public Health (Bangkok) 2004;26(3):277-284. DOI: 10.1093/pubmed/fdh162.
19. Somers TJ, Keefe FJ, Carson JW, et al. Pain catastrophizing in borderline morbidly obese and morbidly obese individuals with osteoarthritic knee pain. Pain Res Manage 2008;13(5):401-406. DOI: $10.1155 / 2008 / 652453$.

20. Sahyoun NR, Hochberg MC, Helmick CG, et al. Body mass index, weight change, and incidence of self-reported physician-diagnosed arthritis among women. Am J Public Health 1999;89(3):391-394. DOI: 10.2105/AJPH.89.3.391.

21. Coggon D, Reading I, Croft $P$, et al. Knee osteoarthritis and obesity. Int J Obes 2001;25(5):622-627. DOI: 10.1038/sj.ijo.0801585.

22. Holliday KL, McWilliams DF, Maciewicz RA, et al. Lifetime body mass index, other anthropometric measures of obesity and risk of knee or hip osteoarthritis in the GOAL case-control study. Osteoarthritis Cartilage 2011;19(1):37-43. DOI: 10.1016/j.joca.2010.10.014.

23. Lohmander LS, De Verdier MG, Rollof J, et al. Incidence of severe knee and hip osteoarthritis in relation to different measures of body mass: a population-based prospective cohort study. Ann Rheum Dis 2009;68(4):490-496. DOI: 10.1136/ard.2008.089748.

24. Gandhi R, Wasserstein D, Razak F, et al. BMI independently predicts younger age at hip and knee replacement. Obesity 2010;18(12):23622366. DOI: $10.1038 /$ oby.2010.72.

25. Changulani M, Kalairajah Y, Peel T, et al. The relationship between obesity and the age at which hip and knee replacement is undertaken. J Bone Joint Surg Br 2008;90(3):360-363. DOI: 10.1302/0301-620X.90B3.19782.

26. Bourne R, Mukhi S, Zhu N, et al. Role of obesity on the risk for total hip or knee arthroplasty. Clin Orthopaed Relat Res 2007;465:185-188. DOI: 10.1097/BLO.0b013e3181576035.

27. Leyland KM, Judge A, Javaid MK, et al. Obesity and the relative risk of knee replacement surgery in patients with knee osteoarthritis: a prospective cohort study. Arthritis Rheumatol 2016;68(4):817-825. DOI: 10.1002 /art.39486.

28. Kessler S, Käfer W. Overweight and obesity: two predictors for worse early outcome in total hip replacement? Obesity 2007;15(11): 2840-2845. DOI: 10.1038/oby.2007.337.

29. Christensen R, Bartels EM, Astrup A, et al. Effect of weight reduction in obese patients diagnosed with knee osteoarthritis: a systematic review and meta-analysis. Ann Rheum Dis 2007;66(4):433-439. DOI: 10.1136/ard.2006.065904.

30. Abu-Abeid S, Wishnitzer N, Szold A, et al. The influence of surgicallyinduced weight loss on the knee joint. Obes Surg 2005;15(10): 1437-1442. DOI: 10.1381/096089205774859281.

31. Must A, Spadano J, Coakley EH, et al. The disease burden associated with overweight and obesity. JAMA 1999;282(16):1523-1529. DOI: 10.1001/jama.282.16.1523. 